\title{
The predicting role of self-efficacyin the Job Demands-Resources Model: A longitudinal study
}

\author{
María Vera ${ }^{1}$, Marisa SALANOVA $^{1}$ AND LAURA LORENTE ${ }^{2}$ \\ ${ }^{1}$ Universitat Jaume I; ${ }^{2}$ Universitat de València
}

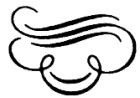

\begin{abstract}
Taking Albert Bandura's Social Cognitive Theory as our starting point, we analysed the predicting role of self-efficacy in the Job Demands-Resources Model. We tested longitudinally the two underlying psychological processes, namely: 1) the motivational process, in which job resources (i.e., job autonomy and social support climate) foster engagement, and 2) the erosion process, in which high job demands (i.e., quantitative overload and role conflict) lead to burnout. Structural equation modelling in a sample of 274 secondary-school teachers confirmed both processes, as well as the powerful predicting role of self-efficacy. Finally, we discuss the theoretical findings and the practical implications.
\end{abstract}

Keywords: Self-efficacy, burnout, engagement.

\section{El papel predictivo de la auto-eficacia en el Modelo de Demandas-Recursos Laborales: un estudio longitudinal}

\section{Resumen}

Con la Teoría Social Cognitiva de Albert Bandura como punto de partida, hemos analizado el rol predictivo de la autoeficacia en el Modelo Demandas-Recursos Laborales. Hemos comprobado longitudinalmente los dos procesos psicológicos subyacentes, a saber: 1) el proceso motivacional, en el que los recursos de trabajo (ej., autonomía en el trabajo y el clima de apoyo social) fomentan el engagement, y 2) el proceso de erosión, en el que las altas demandas laborales (ej., sobrecarga cuantitativa y conflicto de rol) conllevan al desgaste. Mediante ecuaciones estructurales, el modelo fue probado en una muestra de 274 profesores de enseñanza secundaria y se confirmaron ambos procesos, así como el poderoso rol de predicción de la autoeficacia. Finalmente, se discuten los hallazgos teóricos y las implicaciones prácticas.

Palabras clave: Autoeficacia, burnout, engagement.

Author's Address: María Vera, Universitat Jaume I, Department of Psychology, Avda. Vicente Sos Banyat s/n, C.P. 12017 Castellón, Spain. Phone: (+34) 96472 9569; Fax (+34) 96472 9262, E-mail: mvera@uji.es.

Manuscript received: October 4, 2011. Accepted: March 27, 2012. 
Several past studies have confirmed the popular idea that teaching is a stressful job. But teachers also enjoy positive emotions and experiences at work. Thus, we currently know more about the negative side of teachers' well-being and, consequently, it seems interesting to carry out more research on secondary-school teachers that addresses not only the negative part of their jobs, such as burnout (e.g., González-Morales, Rodríguez, \& Peiró, 2010), but also the positive aspects such as engagement (e.g., Bakker, Hakanen, Demerouti, \& Xanthopoulou, 2007).

Hence, in this study, the two sides (i.e., positive and negative) of psychological wellbeing are considered. The first of these two perspectives is by testing whether job resources negatively influence job burnout, as other studies have shown (Hakanen, Bakker, \& Schaufeli, 2006; Llorens, Bakker, Schaufeli, \& Salanova, 2006; Schaufeli \& Bakker, 2004) and the second - and this is what makes this work original - is the inclusion of self-efficacy into the Job Demands-Resources Model (JD-R) (Demerouti, Bakker, Nachreiner, \& Schaufeli, 2001) from the perspective of the Social Cognitive Theory (SCT).

\section{Theoretical background: an integration of the JD-R Model and the SCT}

At the heart of the $J D-R$ Model lies the assumption that, whereas every occupation may have its own specific risk factors associated with job stress, these factors can be classified into two general categories (i.e., job demands and job resources). Job demands refer to "those physical, social, or organizational aspects of the job that require sustained physical and/or psychological (i.e., cognitive and emotional) effort on the part of the employee, and are therefore associated with certain physiological and/or psychological costs" (Demerouti et al., 2001, p. 501). Job resources refer to "those physical, psychological, social, or organizational aspects of the job that may (a) reduce job demands and the associated physiological and psychological costs, (b) are functional in achieving work goals, and (c) stimulate personal growth, learning and development" (Demerouti et al., 2001, p. 501). Based on previous research (Salanova, Llorens, Cifre, Martínez, \& Schaufeli, 2003), we include in this study two of the main job demands of teaching occupations: quantitative overload, and role conflict; and the most important teaching job resources: job autonomy and social support climate.

Moreover, resources are not only necessary to deal with job demands, but they also are important in their own right, and this is in line with the Conservation of Resources Theory (Hobfoll, 2001), which states that the main human motivation is the maintenance and accumulation of resources. Therefore resources are valued for what they are and also because they are a means of achieving or protecting other valuable resources.

Bakker and Demerouti (2007) also emphasized a second premise of the $J D-R$ Model: there are two different underlying psychological processes. Firstly, there is the health impairment or erosion process, in which poorly designed jobs or chronic job demands exhaust employees' mental and physical resources and may therefore lead to the depletion of energy and health problems. Secondly, we find the motivational process, whereby it is assumed that job resources have motivational potential and lead to high work engagement, low cynicism, and excellent performance.

This model includes a significant qualitative change when Xanthopoulou, Bakker, Demerouti and Schaufeli (2007) expand the $J D-R$ Model by examining the relationship between personal resources and the model's processes. We understand personal resources as aspects of the self that are generally linked to resiliency and refer to individuals' sense of their ability to control and have an impact on their environment successfully (Hobfoll, Johnson, Ennis, \& Jackson, 2003). Xanthopoulou et al. (2007; 2009) included three personal resources in their studies: self-efficacy, organizational-based self-esteem, and optimism. They showed that personal resources played a significant and a mediating role in the $J D-R$ Model. In their model, they argued that personal resources mediate the relationship between job resources and engagement on the one hand, and job demands 
and exhaustion on the other hand. But also, they found that personal resources influence the perception of job resources, acting as antecedents.

Moreover, in a two waves study, Xanthopoulou et al. (2009) stated that there are reciprocal relationships, between personal and job resources and engagement, that is, these reciprocal relationships are tested in the motivational process of the JD-R model. In the same line, Lorente, Salanova, Martínez and Schaufeli (2008) also added personal resources (i.e., perceived mental and emotional competences) to the $J D-R$ Model, they found that the role of personal resources as a significant predictor in the JD-R model disappears when controlling for baseline levels of burnout and engagement at T1.

The present study is focused in the role played by self-efficacy, defined as "beliefs in one's capabilities to organize and execute courses of action required to produce certain achievements or results" (Bandura, 1997, p.3), within the JD-R Model, since it is the most powerful personal resource. According to the SCT, self-efficacy explains people's behaviors and the antecedents and consequences of their behaviors. We start from the assumption that efficacy beliefs play a predicting role and not a mediating role, since the SCT efficacy beliefs are considered to be predictors of human behavior, motivation and even of how we feel in different contexts, including the workplace. According to Bandura and regarding our own behavior, we tend to choose those tasks that we are able to do and avoid those which exceed our capabilities. Efficacy beliefs also determine the amount of effort spent on dealing with obstacles and the amount of time or persistence invested in trying to achieve something. Low levels of self-efficacy are associated with early retirements, while high levels involve effort and perseverance.

Hence, people who are considered inefficacious in coping with the demands of the environment, exaggerate the magnitude of their deficiencies and the potential difficulties of the medium. These negative thoughts generate stress and hinder the use of available resources, while people who perceive themselves as efficacious focus their efforts on the demands that may arise from situations and strive to resolve them correctly. In this regard, research has shown that self-efficacy is associated with persistence, commitment, satisfaction with the actions we perform and human motivation (Salanova, Schaufeli, Xanthopoulou, \& Bakker, 2010).

\section{Teacher's well-being: burnout and engagement}

Although a considerable amount of research has been devoted to studying teacher burnout (e.g., Skaalvik \& Skaalvik, 2010) it is still unclear exactly what the best way to help teachers prevent burnout is (Lambert \& McCarthy, 2006). According to McCarthy, Lambert, O'Donnell and Melendres (2009), this may be because job burnout studies, over the past 30 years, have focused on workplace conditions (e.g., lack of job role specification, layoffs), as the cause of burnout rather than on intra- and interpersonal factors. This is why, in this article, we have focused not only on workplace conditions like quantitative overload and autonomy, but also on personal (i.e., personal resources) and interpersonal factors (i.e., role conflict and social climate) in the prediction of teacher burnout.

Although burnout has been traditionally defined as "a prolonged response to chronic emotional and interpersonal stressors on the job, and is defined by the three dimensions of exhaustion, cynicism and professional inefficacy" (Maslach, Schaufeli, \& Leiter, 2001, p. 397). It is important to note that recent research on burnout considers the inclusion of the structure based on four dimensions of burnout (i.e., emotional exhaustion, depersonalization, cynicism, and lack of professional efficacy) confirmed by Salanova et al. (2005). They understand both dimensions as indicators of a second-order factor called mental distance "toward work" (cynicism) and mental distance "toward fellow workers and the people for whom one works" (depersonalization). 
Moreover, professional efficacy is not considered in this study as a dimension of burnout for two reasons. Firstly, from a conceptual point of view, instead of a genuine burnout dimension, professional efficacy has been considered to be similar to a personality construct (Cordes \& Dougherty, 1993). Secondly, some etiological models also posit that burnout develops out of feelings of inefficiency and that it can therefore be considered a crisis of professional efficacy (Llorens, García, \& Salanova, 2005; Salanova et al., 2003; Salanova, Peiró, \& Schaufeli, 2002; Van Dierendonck, Schaufeli, \& Buunk, 2001).

Finally, as we mentioned above, positive well-being has not been studied so much in past research as, for example, teacher engagement. Work engagement is defined by Schaufeli, Salanova, González-Romá and Bakker (2002, p. 72) as a "positive, fulfilling, work-related state of mind that is characterized by vigor, dedication, and absorption". Engagement refers to a persistent and pervasive affective-cognitive state that is not focused on any particular object, event, individual, or behavior. As in the case of burnout, here we have used the core of engagement (i.e., vigor and dedication).

A growing body of evidence supports the relationship between engagement of the employee at work and organizational outcomes (cf. Simpson, 2009). Moreover, work engagement has been widely studied within the $J D-R$ Model, and there are several studies that underline engagement as a result of both job and personal resources. For instance, Bakker, Schaufeli, Leiter and Taris (2008) concluded that engagement is a unique concept which is best predicted by job and personal resources. Salanova et al. (2010) clearly summarize the latest findings about work engagement from three theoretical perspectives (i.e., Conservation of Resources, SCT, and Broaden-and-Build theory), concluding that there are reciprocal and positive relationships among resources and engagement. These same authors also speculated that there is a positive cycle that includes job resources, personal resources, positive emotions, work engagement and enhanced performance. Moreover, they stated that self-efficacy initiates gain spirals.

Although testing these spirals in our sample is impossible since a minimum of three waves are necessary (Lindsley \& Brass, 1995), the general objective of the current study is to test the $J D-R$ Model by including self-efficacy as a predictor of the motivational and erosion processes, integrating two of the major theoretical perspectives in Occupational Health Psychology (i.e., the JD-R Model and the SCT). Not without first checking that self-efficacy play indeed a predicting role and not a mediating role within the two processes of the $J D-R$ Model. Specifically we expect two partial mediations since it has been tested that there are a relationship between self-efficacy and burnout (Skaalvik \& Skaalvik, 2010) on the one hand; and between self-efficacy and work engagement (Halbesleben, 2010) on the other hand. Accordingly, our hypotheses are:

$\mathrm{H}_{1}$ : Job demands at T2 will partially mediate the relationships between self-efficacy at $\mathrm{T} 1$ and burnout at $\mathrm{T} 2$.

$\mathrm{H}_{2}$ : Job resources at T2 will partially mediate the relationships between self-efficacy at $\mathrm{T} 1$ and engagement at $\mathrm{T} 2$.

Moreover, we will test this predicting role in the whole model, so we expect that:

$\mathrm{H}_{3}$ : Self-efficacy predicts: 1) Burnout indirectly via job demands and resources over time; and 2) Engagement indirectly via job resources over time.

Specifically we expect that:

$\mathrm{H}_{3 \mathrm{a}}$ : Feeling high in self-efficacy at T1 has a negative, but indirect, influence on burnout at T2 via job demands at T2. The higher self-efficacy is, the lower job demands and burnout over time.

$\mathrm{H}_{3 \mathrm{~b}}$ : Feeling high in self-efficacy at T1 has a negative, but indirect, influence on burnout at $\mathrm{T} 2$ via job resources at $\mathrm{T} 2$. The higher self-efficacy is, the higher job resources and the lower burnout over time

$\mathrm{H}_{3 \mathrm{c}}$ : Feeling high in self-efficacy at T1 has a positive, but indirect, influence on engagement at T2 via job resources at T2. The higher self-efficacy is, the higher job resources and engagement over time. 


\section{METHOD}

\section{Participants and procedure}

A longitudinal study was performed among Spanish secondary-school teachers. This longitudinal study had two waves, the first one (T1) at the beginning of the academic year, and the second one (T2) eight months later at the end of the academic year. In order to obtain our sample, we sent a letter to 600 secondary teachers from 50 secondary schools explaining the purpose of the research, together with the self-report questionnaires. Teachers interested in participating in our study only had to return the completed questionnaire. At T1, it was returned by 484 teachers from 34 schools, while at T2, after resending the questionnaire out to be completed again, it was completed by 274 teachers ( $57 \%$ women and $43 \%$ men) from 23 schools. Thus, the final sample was composed of 119 men (43\%) and 155 women $(57 \%)$ with a mean age of 40 years $(S D=7.01)$.

To control for potential selection bias due to panel loss, we examined whether teachers from the panel group $(N=274)$ differed from the dropouts $(N=210)$ with respect to their baseline levels on the study variables. Results of multivariate analyses of variance showed that the two samples did not differ in terms of their demographic characteristics, that is, age: $F(1,482)=.27, p=.61$; gender: $F(1,482)=, 01 p=.91$; type of school (private vs. public): $F(1,482)=2.05, p=.15$; teaching experience: $F(1,482)=2.37, p=$ .13 ; organizational tenure: $F(1,482)=1.63, p=.20$, or in the other variables of the model, namely, self-efficacy: $F(1,482)=1.40, p=.24$; job resources: $F(1,482)=.16, p$ $=.69$; job demands $F(1,482)=6.65, p=.01$; burnout: $F(1,482)=2.85, p=.92$; and work engagement $F(1,482)=2.38, p=.12$. Although in the case of job demands there were significant differences, taken as a whole there are no major differences in the results, and thus there is no selection bias in this study.

\section{Instruments}

Job demands. Quantitative overload was measured with the questionnaire by Beehr, Walsh and Taber (1976), which includes three items (e.g., "I have too much work to be able to do it absolutely well"). Role conflict was measured using the eight-item scales by Rizzo, House and Lirtzman (1970) (e.g., "I do what is acceptable for some people but not for others"). Items on both scales were scored according to a seven-point Likert format, ranging from0 (not described at all) to 6 (fully describes).

Job resources. Autonomy was measured using the questionnaire by Jackson, Wall, Martin and Davis (1993) consisting of five items (e.g., "I can decide what tasks I will do everyday"). We measured climate using the FOCUS questionnaire (Van Muijen et al., 1999). Support climate was measured by three items (e.g., "People help each other to finish the work correctly"). Goals climate was measured by three items (e.g., "The targets to be achieved over a period of time are clearly defined"). Innovation climate was measured by three items (e.g., "New ideas are implemented to improve work"). Finally, rules climate was measured by three items (e.g., "Work is highly regulated"). Items on all scales were scored according to a seven-point Likert format ranging from 0 (not described at all) to 6 (fully describes).

Self-efficacy was measured with a specific version of the generalized self-efficacy scale (Schwarzer, Schmitz, \& Daytner, 1999) that was adapted to the work context. The 10 items were reworded to fit the work-specific situation (e.g., "I can solve difficult problems in my work if I try"). The items were scored according to a seven-point Likert format ranging from 0 (not at all) to 6 (totally).

Burnout. The three dimensions were measured using different versions of the Maslach Burnout Inventory (MBI). Exhaustion and cynicism were measured using the Spanish version (Salanova, Schaufeli, Llorens, Peiró, \& Grau, 2000) of the MBI-GS (Schaufeli et al., 2002) using five (e.g., "I am emotionally exhausted by my work") and four items 


\section{Estudios de Psicología, 2012, 33 (2), pp. 167-178}

(e.g., "I have lost interest in my work since I began this job") respectively. And we used the five-item MBI-HSS scale by Maslach, Jackson and Leiter (1996) to measure depersonalization (e.g., "I really do not mind what will happen to some people who I must work for in my work"). The items of the dimensions were scored according to a seven-point Likert format ranging from 0 (never/not at all) to 6 (always/everyday).

Work Engagement. The vigor and dedication dimensions were measured using the Spanish adaptation (Salanova et al., 2000) of the Utrecht Work Engagement Scale (UWES) (Schaufeli et al., 2002) made up of six items that measure vigor (e.g., "In my work, I feel full of energy") and five for dedication (e.g., "My work is challenging"). The items of the dimensions were scored according to a seven-point Likert format ranging from 0 (never/not at all) to 6 (always/everyday).

\section{Data analyses}

Firstly, we performed descriptive analyses by computing the mean, standard deviation and internal consistency for each scale and their intercorrelations. Secondly, in order to test the mediation effects formulated in Hypothesis $1 \mathrm{a}$ and $1 \mathrm{~b}$ we followed Baron and Kenny's approach (1986), using structural equation modeling (SEM) techniques, using the AMOS software package (Arbuckle, 2005). Thirdly, we also employed SEM techniques using the AMOS software package to test $\mathrm{H}_{2}$ and $\mathrm{H}_{3}$ (see Figure 1). The goodness-of-fit of the models was evaluated using absolute and relative indexes. The three absolute goodness-of-fit indexes that were calculated were: (1) the $\chi^{2}$ goodness-of-fit statistic; (2) the Goodness-of-Fit Index (GFI); and (3) the Root Mean Square Error of Approximation (RMSEA). Additionally, we computed a relative index: Comparative Fit Index (CFI). Because the distribution of the GFI is unknown, no statistical test or critical value is available (Jöreskog \& Sörbom, 1993). Values below .06 for the RMSEA are indicative of an acceptable fit (Hu \& Bentler, 1999), whereas a cut-off value close to .95 for CFI is considered to indicate an adequate model fit (Hu \& Bentler, 1999).

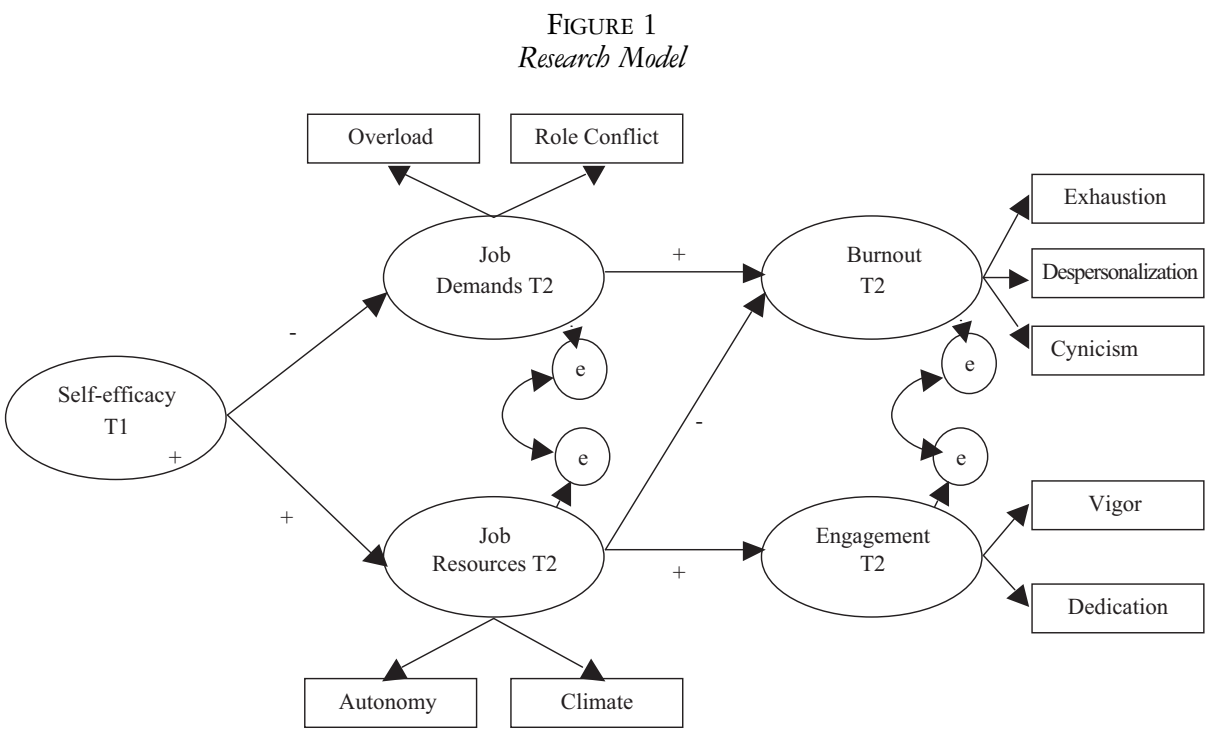

\section{RESULTS}

\section{Descriptive analyses}

Means and standard deviations of the variables, along with the internal consistencies of the scales, are presented in Table I. Moreover, the same table shows 


\begin{tabular}{|c|c|c|c|}
\hline & 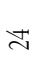 & 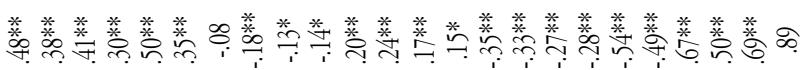 & $\|$ \\
\hline & $\approx$ & 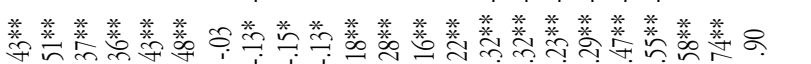 & $\dot{\tilde{H}} \| \tilde{N}$ \\
\hline & & 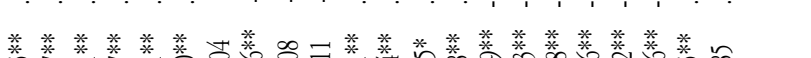 & 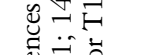 \\
\hline & ป & 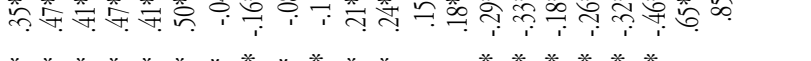 & 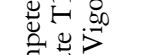 \\
\hline & $\vec{\sim}$ & 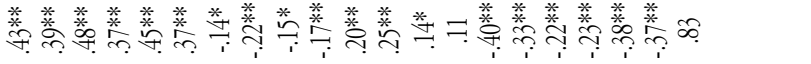 & $\stackrel{0}{8}$. \\
\hline & ฉి & 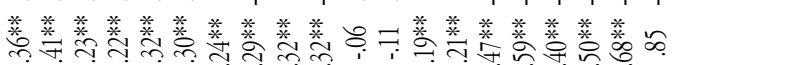 & 急 \\
\hline & & $\because \cos$ & $\stackrel{2}{*}$ \\
\hline & $\curvearrowright$ & 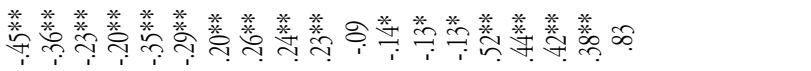 & 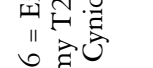 \\
\hline & $\stackrel{\infty}{\oplus}$ & 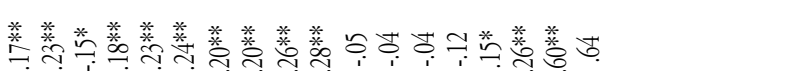 & 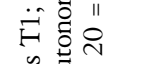 \\
\hline & & * * & 岛焉芦 \\
\hline & $\Xi$ & 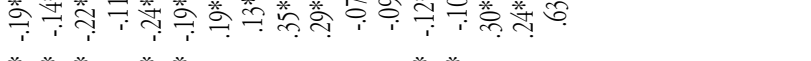 & 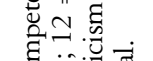 \\
\hline & $\because$ & 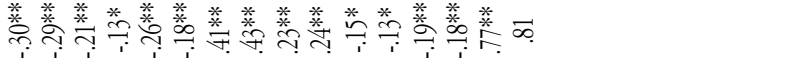 & 总芦芯 \\
\hline$\underset{\curvearrowright}{\curvearrowright}$ & $\simeq$ & 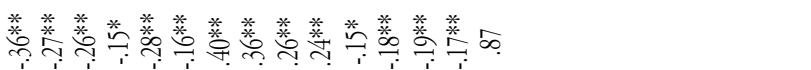 & 范 \\
\hline & $\Xi$ & 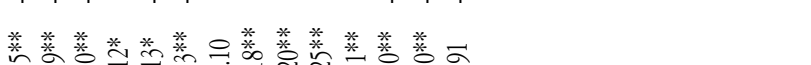 & \\
\hline$\underset{3}{3}$ & \pm & 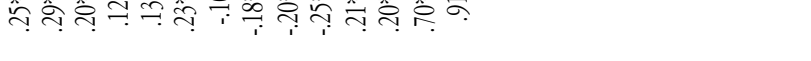 & $\tilde{c}=\frac{\pi}{2}=\frac{\pi}{2}$ \\
\hline$\sqrt[3]{3}$ & $\approx$ & 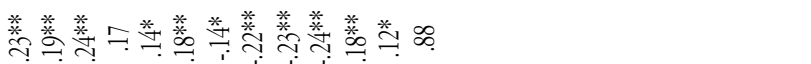 & \\
\hline$\sqrt{3}$ & $\simeq$ & 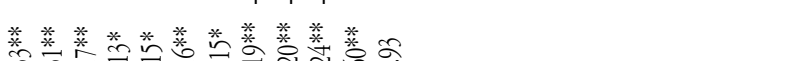 & \\
\hline 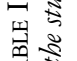 & & 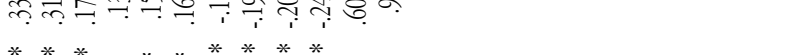 & \\
\hline 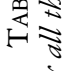 & $=$ & 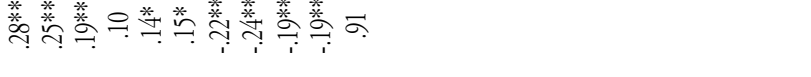 & 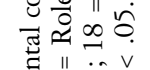 \\
\hline$\stackrel{5}{3}$ & 은 & 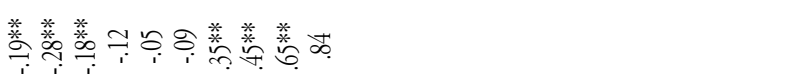 & \\
\hline 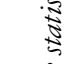 & a & 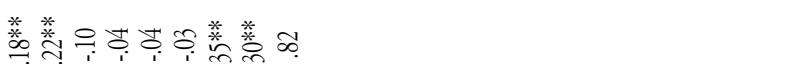 & $\vec{F} . \breve{G}$ \\
\hline 竞 & $\infty$ & 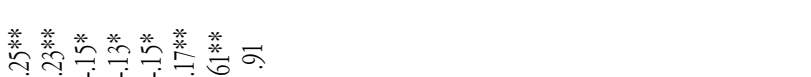 & 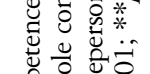 \\
\hline & & 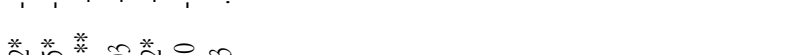 & 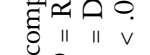 \\
\hline & 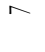 & $\tilde{7}$ & 焉余云 \\
\hline & 6 & 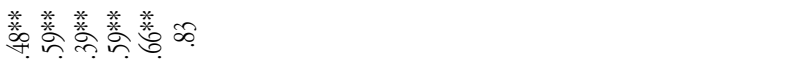 & 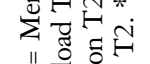 \\
\hline & $n$ & 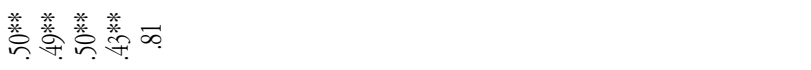 & 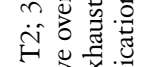 \\
\hline & 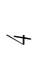 & 桊蔁蓄下 & 氖.苞 \\
\hline & m & 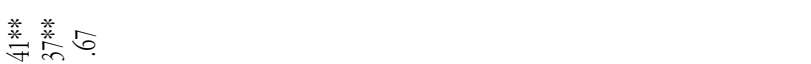 & 嵌 \\
\hline & $\sim$ & 密过 & $\therefore 9$ \\
\hline & & & \\
\hline & - & $\approx$ & 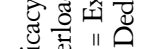 \\
\hline & $\therefore$ & bo & \\
\hline & $\Sigma$ & 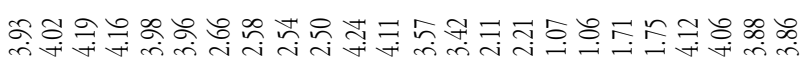 & \\
\hline & & & ฉัँ \\
\hline
\end{tabular}




\section{Estudios de Psicología, 2012, 33 (2), pp. 167-178}

all the correlations between the variables, which were significant and in the expected direction. Therefore, the higher self-efficacy are at both times, the higher job resources and engagement will be at both times, and the fewer job demands and less burnout there will be at both times.

\section{Model Testing}

In order to test the mediation effects formulated in Hypothesis $1 \mathrm{a}$ and $1 \mathrm{~b}$ we followed Baron and Kenny's approach (1986), according to which there are four steps in establishing a significant mediation effect. First, there must be a significant relationship between the predictor and the outcome. Second, the predictor must be significantly related to the mediator. Third, the mediator should be significantly related to the outcome variable. Finally, there is a significant mediation effect when the relationship between the predictor and the outcome becomes significantly weaker (partial mediation) or non significant (full mediation), after the inclusion of the mediator. The Sobel z test was used to examine the significance of the indirect effect.

Regarding $\mathrm{H}_{1 \mathrm{a}}$, preliminary results showed that self-efficacy at time 1 were related to both burnout at time $2(\beta=-.39, p<.001)$ and job demands at time $2(\beta$ $=-.35, p<.001)$ and that job demands at time 2 were related to burnout at time 2 $(\beta=.57, p<.001)$. Moreover, the Full Mediation model $\left(\mathrm{M}_{1}\right)$ (see Table II) has, generally speaking, a satisfactory fit to the data. However, and according to our hypothesis, results of the difference test suggested that the Partial Mediation model $\left(\mathrm{M}_{2}\right)$ fit better $\left(\Delta \chi^{2}(1)=11.22, p<.001\right)$. Furthermore, the path coefficients of $\mathbf{M}_{2}$ from self-efficacy at time 1 to job demands at time $2(\beta=-.36, p<.001)$, from job demands at time 2 to burnout at time $2(\beta=.47, p<.001)$, and from self-efficacy at time 1 to burnout at time $2(\beta=-.27, p<.001)$ were all statistically significant and in the expected direction. Besides, the addition of the job demands at time 2 in the model reduced the magnitude of the direct association between self-efficacy at time 1 and burnout at time 2 significantly (from $\beta=-.39, p<.001$ to $\beta=-.27, p<.001$; $Z=-3.25, p<.001)$.

Furthermore, in Table II, we can see the Alternative Model, in which self-efficacy played a mediating role and not the expected predicting role. At first glance we can see that the fit indices of both, the Full $\left(\mathbf{M}_{3}\right)$ and the Partial $\left(\mathbf{M}_{4}\right)$ mediation are better in the $\mathrm{M}_{1}$ and $\mathrm{M}_{2}$ respectively. Thus, our findings support the partial mediation effect of Hypothesis 1.

Regarding $\mathrm{H}_{1 \mathrm{~b}}$, preliminary results showed that self-efficacy at time 1 were related to both work engagement at time $2(\beta=.63, p<.001)$ and job resources at time $2(\beta=.76$, $p<.001)$ and that job resources at time 2 were related to work engagement at time 2 ( $\beta$ $=.76, p<.001)$. Moreover, the Full Mediation model $\left(\mathrm{M}_{5}\right)$ (see Table II) has a more than satisfactory fit to the data. However, results of the difference test suggested that the Partial Mediation model $\left(\mathrm{M}_{6}\right)$ did not lead to a significant improvement of the fit, $\left(\Delta \chi^{2}(1)\right.$ $=2.67$; n.s.). Moreover, the path coefficients of $\mathrm{M}_{6}$ from self-efficacy at time 1 to job resources at time $2(\beta=.76, p<.001)$, from job resources at time 2 to work engagement at time $2(\beta=.51, p<.001)$, and from self-efficacy at time 1 to work engagement at time $2(\beta=.27$; n.s.) were all in the expected direction. Besides, the addition of the job resources at time 2 in the model reduced the magnitude of the direct association between self-efficacy at time 1 and work engagement at time 2 significantly (from $\beta=.63, p<$ .001 to $\beta=.27$; n.s.; $\mathrm{Z}=2.02, p<.05$ ).

Furthermore, in Table II, we can see the Alternative Model, in which self-efficacy played a mediating role and not the expected predicting role. At first glance we can see that the fit indices of both, the Full $\left(\mathbf{M}_{7}\right)$ and the Partial $\left(\mathrm{M}_{8}\right)$ mediation are better in the $\mathrm{M}_{5}$ and $\mathrm{M}_{6}$ respectively. Thus, our findings support the partial mediation effect of Hypothesis 2. 
Self-efficacy in the JD-R Model / M. Vera et al.

TABLE II

Results of Structural Equation Modeling $(N=274)$. Self-efficacy: predicting or mediating role in the $J D-R$ Model

$\chi^{2} \quad d f \quad$ GFI RMSEA CFI $\quad \Delta \chi^{2} \quad \Delta d f$

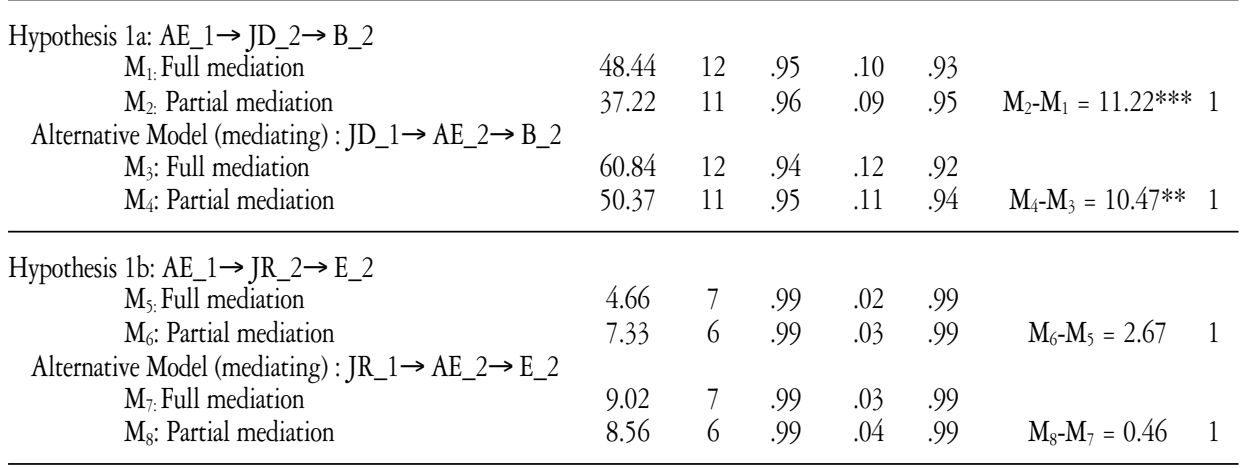

Note: $. A E \_1=$ Self-efficacy Time 1; AE_2 = Self-efficacy Time 2; JD_1 = Job Demands Time 1; JD_2 = Job Demands Time 2; B_2 = Burnout Time 2; JR_1= Job Resources Time 1; JR_2= Job Resources Time 2; E_2 = Engagement Time 2 . $* * * p<.001 ; * * p<.005 ; * p<.05$.

Finally, once the predicting role of self-efficacy has been tested separately in each process of the $J D-R$ Model, that is the motivational and the erosion one. And, in order to test our model in a whole way (see Figure 1), therefore, our Hypotheses 2 and 3, SEM method, as implemented by the AMOS software program (Arbuckle, 2005) using Maximum Likelihood Estimation methods, was used to establish the relationships between the model variables. The fit indices of the model are: ${ }^{2}(38)=76.38, \mathrm{GFI}=.95, \mathrm{RMSEA}=.06, \mathrm{CFI}$ $=.95$. As we can see, the model fit satisfactorily. The model can be seen in Figure 2 .

FIGURE 2

Model Testing $(N=274)$

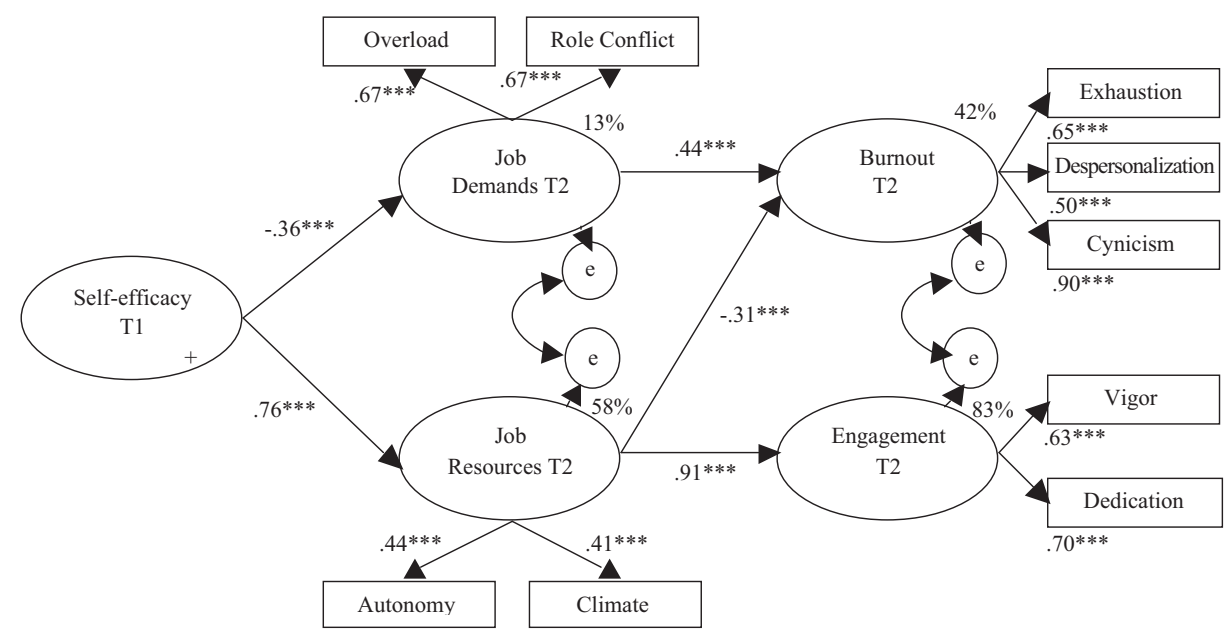

\section{DISCUSSION}

The purpose of this article was to test the capacity of the $J D-R$ Model (Demerouti et al., 2001) to explain the impact that job demands and resources have on teachers' well- 


\section{Estudios de Psicología, 2012, 33 (2), pp. 167-178}

being (i.e., burnout and engagement) over time, and, more importantly, to examine the predicting role of self-efficacy within the framework of the $S C T$, in a longitudinal study of 274 secondary-school teachers at two waves.

Throughout this article we have shown that the literature agrees on the importance of introducing personal resources such as self-efficacy into the $J D-R$ Model (Xanthopoulou et al., 2007). However, there are also contradictions in the literature as regards the role that personal resources play in the model: a mediating role (Xanthopoulou et al., 2009); or a predicting role (Lorente et al., 2008). However, there is some agreement (Salanova et al., 2010; Xanthopoulou et al., 2009), on the existence of the reciprocal and positive relationships among resources and engagement. More specifically, Salanova et al. (2010) also speculated that there is a positive cycle that includes job resources, personal resources, positive emotions, work engagement and enhanced performance, in which self-efficacy initiates gain spirals. However there is no literature, as far we know, that test the role of self-efficacy in the erosion process of the $J D-R$ Model in a longitudinal study.

Our results confirm our hypotheses 1 and 2, stressing that self-efficacy plays a predicting role in the development of the motivational and erosion processes of burnout and engagement at work in line with the SCT. Thus, people with high efficacy beliefs feel they have enough capacity and skills to meet any job demand and to recognize and know how to use the job resources that are also available. Regarding this issue, it is important to stress that, as we can see in Table II, although all indexes fit better in the case of the predicting role, in the case of the relationship between self-efficacy, job resources and work engagement, the alternative model (i.e., the mediating role) has also a good fit to the data which is in line with Xanthopoulou et al. (2007).

We have also confirmed that teachers high in self-efficacy at T1 have a negative, but indirect, influence on burnout at T2 via job demands at T2. Hence, the higher selfefficacy is, the lower job demands and the lower burnout over time $\left(\mathrm{H}_{3 \mathrm{a}}\right.$ confirmed). Moreover, teachers high in self-efficacy at T1 have also a negative, but indirect, influence on burnout at T2 via job resources at T2. Hence, the higher self-efficacy is, the higher job resources and the lower burnout over time $\left(\mathrm{H}_{3 \mathrm{~b}}\right.$ confirmed). As Llorens et al. (2006) explained, these results suggest that job resources influence well-being via two different ways: directly through increased engagement and indirectly by reducing burnout.

Furthermore, according to our Hypotheses $3_{c}$ teachers high in self-efficacy at T1 have a positive, but indirect, influence on engagement at T2 via job resources at T2. Hence, the higher self-efficacy is, the higher job resources and engagement over time $\left(\mathrm{H}_{3 c}\right.$ confirmed).

\section{Theoretical contributions}

We have shown that the $J D-R$ Model is parsimonious and capable of integrating a wide range of potential applications and resources, as well as strong theoretical backgrounds such as the SCT, integrating two of the major theoretical perspectives in Occupational Health Psychology (i.e., the JD-R Model and the SCT).

Our results reconfirmed what other authors (e.g., Hakanen et al., 2006) had claimed about the importance of job resources, which not only trigger engagement, but also reduce burnout. And this is in line with the assumptions of the Conservation of Resources (COR) Theory which predicts that those who possess more resources are also more capable of gaining resources (Salanova et al., 2010).

\section{Implications for future research and for practice}

It is important for future research to examine whether self-efficacy play a predicting role in the $J D-R$ Model in other occupations, and also in other types of teachers, such as primary school teachers, university faculty members, and so forth. Moreover, it would also be interesting to study this interaction between the JD-R Model and the SCT with 
more than two waves, in order to test the existence of the gain spiral in each process of the $J D-R$ Model

With regard to practical implications, this study shows us how important it is to encourage high-resource teachers, which includes both personal and job resources as a source of well-being that help teachers to be more engaged in their work and therefore less liable to suffer from burnout. It might be a good idea to promote workshops in schools about increasing self-efficacy, as well as promoting autonomy and a good climate among teachers.

\section{Weaknesses and strengths of the study}

The main limitation of this study is the stability of our measures. As we can see in Table I, there are almost no differences between values at time 1 and 2. Because of this stability over time, we have not been able to test the model with all variables at two times together, because suppressor effects would appear. The solution to this problem would be to use more specific measures of the task, such as specific task self-efficacy or task engagement instead of work engagement. Moreover, observations were based solely on self-reports, which might have inflated the relationships among the variables, however, the longitudinal design overcomes some of the problems of common method variance.

But our study also has its strengths, the first of which is the use of longitudinal research designs that test the cross-lagged effects between two waves. Second, the test of the predicting role of personal resources was carried out using two types of structural equations, one using the Baron and Kenny's approach (1986), and the second one the whole model. Finally, we have obtained interesting results for practice.

\section{References}

ArbuCKLE, J. L. (2005). Amos 6.0 user's guide. Chicago, IL: SPSS.

Bakker, A. B., \& Demerouti, E. (2007). The Job Demands-Resources model: state of the art. Journal of Managerial Psychology, 22, 309-328.

Bakker, A. B., Hakanen, J. J., Demerouti, E., \& Xanthopoulou, D. (2007). Job resources boost work engagement particularly when job demands are high. Journal of Educational Psychology, 99, 274-284.

Bakker, A. B., Schaufeli, W. B., Leiter, M. P., \& TAris, T. W. (2008). Work engagement: An emerging concept in occupational health psychology. Work E Stress, 22, 187-200.

BANDurA, A. (1997). Self efficacy: The exercise of control. New York, NY: Freeman.

BARON, R. M., \& KENNY, D. A. (1986). The moderator-mediator variable distinction in social psychological research: Conceptual, strategic, and statistical considerations. Journal of Personality and Social Psychology, 51, 1173-1182.

Beehr, T. A., Walsh, J. T., \& TABer, T. D. (1976). Relationship of stress to individually and organizationally valued states: Higher order needs as a moderator. Journal of Applied Psychology, 61, 41-47.

Cordes, C. L. \& Dougherty, T. W. (1993). A review and integration of research on job burnout. Academy of Management Review, 18, 621-656.

Demerouti, E., Bakker, A. B., Nachreiner, F., \& Schaufeli, W. B. (2001). The Job Demands-Resources Model of Burnout. Journal of Applied Psychology, 86, 499-512.

González-Morales, M. G., Rodríguez, I. \& Peiró, J. M. (2010). A Longitudinal Study of Coping and Gender in a Female-Dominated Occupation: Predicting Teachers' Burnout. Journal of Occupational Health Psychology, 15, 29-44.

Halbesleben, J. R. B. (2010). A meta-analysis of work engagement: Relationships with burnout, demands, resources and consequences. In A. Bakker and M. Leiter (Eds), Work engagement: A Handbook of Essential theory and research (pp. 102-117). New York: Psychology Press.

HAKANEN, J., BAKKER, A. B., \& SCHAUfELI, W. B. (2006). Burnout and work engagement among teachers. Journal of School Psychology, 43, 495-513.

Hobfoll, S. E. (2001). The influence of culture, community, and the nested-self in the stress process: advancing conservation of resources theory. Applied Psychology: An International Review, 50, 337-370.

Hobfoll, S. E., Johnson, R. J., EnNis, N., \& JACKson, A. P. (2003). Resource loss, resource gain, and emotional outcomes among inner city women. Journal of Personality and Social Psychology, 84, 632-643.

Hu, L. T., \& Bentler, P. M. (1999). Cut off criteria for fit indexes in covariance structure analysis: Conventional criteria versus new alternatives. Structural Equation Modeling, 6, 1-55. 
178 Estudios de Psicología, 2012, 33 (2), pp. 167-178

Jackson, P. R., Wall, T. D., Martin, R., \& Davis, K. (1993). New measures of job control, cognitive demand and production responsibility. Journal of Applied Psychology, 78, 753-762.

JÖRESKOG, K. G., \& SÖRBOM, D. (1993). LISREL 8: Structural equation modeling with the SIMPLIS command language. Chicago: Scientific Software International.

LAMBERT, R. G., \& MCCARTHY, C. J. (2006). Understanding teacher stress in an era of accountability. Greenwich, CT: Information Age.

Lindsley, D. H., \& Brass, D. J. (1995). Efficacy-Performing Spirals: a Multilevel Perspective. Academy of Management Review, 20, 645-678.

Llorens, S., Bakker, A., Schaufeli, W. B., \& Salanova, M. (2006). Testing the robutness of the 'Job Demands-Resources' Model. International Journal of Stress Management, 13, 378-391.

Llorens, S., García, M., \& Salanova, M. (2005). Burnout como consecuencia de una crisis de eficacia: un estudio longitudinal en profesores de Secundaria. [Burnout as a result of a crisis of efficacy: a longitudinal study among secondary teachers]. Revista de Psicología del Trabajo y las Organizaciones, 21, 55-70.

Lorente, L., Salanova, M., Martínez, I. M., \& Schaufeli, W. B. (2008). Extension of the Job DemandsResources model in the prediction of burnout and engagement among teachers over time. Psicothema, 20, 354-360.

Maslach, C., Jackson, S. E., \& LeIter, M. P. (1996). Maslach Burnout Inventory: Manual (3 ${ }^{\text {rd }}$ ed.). Palo Alto, CA: Consulting Psychologist Press.

Maslach, C., SCHaufeli, W. B., \& Leiter, M. P. (2001). Job Burnout. Annual review of psychology, 52, 397422.

MCCARThy, C., LAmbert, R., O’Donnell, M., \& MELEndRes, L. (2009). The relation of elementary teachers' experience, stress, and coping resources to burnout symptoms. The Elementary School Journal, 109, 1-19.

Rizzo, J., House, R. J., \& LiRTzMAN, S. I. (1970). Role conflict and ambiguity in complex organizations. Administrative Science Quarterly, 15, 150-163.

Salanova, M., Llorens, S., Cifre, E., Martínez, I. M., \& Schaufeli, W. B. (2003). Perceived collective efficacy, subjective well-Being and task performance among electronic work groups: an experimental study. Small Group Research, 34, 43-73.

Salanova, M., Llorens, S., García, M., Burriel, R., Bresó, E., \& Schaufeli, W. B. (2005). Towards a four dimensional model of burnout: A multigroup factor-analytic study including depersonalization and cynicism. Educational and Psychological Measurement, 65, 901-913.

Salanova, M., Peiró, J. M., \& SChaufeli, W. B. (2002). Self-efficacy specificity and burnout among information technology workers: An extension of the Job Demands- Control Model. European Journal of Work and Organizational Psychology, 11, 1-25.

Salanova, M., Schaufeli, W. B., Llorens, S., Peiró, J. M., \& Grau, R. (2000). Desde el 'burnout' al 'engagement': ¿una nueva perspectiva? [From burnout to engagement: a new perspective?] Revista de Psicología del Trabajo y las Organizaciones, 16, 117-134.

Salanova, M., Schaufeli, W. B., Xanthopoulou, D., \& BAKker, A. (2010). The gain spiral of resources and work engagement: Sustaining a positive worklife. In A. Bakker and M. Leiter (Eds.), Work engagement: A Handbook of Essential theory and research (pp. 118-132). New York: Psychology Press.

SCHAUFELI, W. B. \& BAKKER, A. B. (2004). Job demands, job resources, and their relationship with burnout and engagement: A multi-sample study. Journal of Organizational Behavior, 25, 293-315.

Schaufeli, W. B., Salanova, M., González-Romá, V., \& BakKer, A. (2002). The measurement of burnout engagement: A confirmatory factor analytic approach. Journal of Happiness Studies, 3, 71-92.

Schwarzer, R., Schmitz, G. S., \& Daytner, G. T. (1999). The Teacher Self-Efficacy scale. [On-line publication]. Retrieved January 14, 2008, from http://www.fuberlin.de /gesund/teacher-selfefficacy.html.

SIMPSON, M. R. (2009). Engagement at work: A review of the literature. International Journal of Nursing Studies 46, 1012-1024.

SkAAlviK, E. M. \& SKAAlviK, S. (2010). Teacher self-efficacy and teacher burnout: A study of relations Teaching and Teacher Education, 26, 1059-1069.

Van Dierendonck, D., SChaufeli, W. B., \& Buunk, B. P. (2001). Towards a process model of burnout: Results from a secondary analysis. European Journal of Work and Organizational Psychology, 10, 41-52.

Van Muijen, J. J., Kopman, P., De Witte, K., De Cock, G., Susanj, Z., Lemoine, F., Bourantes, D., Papalexandris, N., Branyicski, I., Spaltro, E., Jesuino, J., GonZalevs das Neves, J., Pitariu, H., Konrad, E., Peiró, J. M., GonZÁlez-Romá, V., \& Turnipseed, D. (1999). Organizational Culture: The FOCUS questionnaire. European Journal of Work and Organizational Psychology, 8, 551-568.

Xanthopoulou, D., Bakker, A. B., Demerouti, E., \& Schaufeli, W. B. (2007). The role of personal resources in the job demands-resources model. International Journal of Stress Management, 14, 121-141.

Xanthopoulou, D., Bakker, A. B., Demerouti, E., \& Schaufeli, W. B. (2009). Reciprocal relationships between job resources, personal resources and work engagement. Journal of Vocational Behavior, 74, 235244. 